\title{
Abortion and regret
}

\author{
Kate Greasley
}

\section{Correspondence to}

Kate Greasley, New College, Holywell Street, Oxford OX1 3BN, UK;

kate.greasley@new.ox.ac.uk

Received 25 January 2012 Accepted 27 June 2012 Published Online First 28 August 2012

\section{CPLinked}

- http://dx.doi.org/10.1136/ medethics-2012-100993

\section{ABSTRACT}

The article considers three theses about postabortion regret which seek to illustrate its pertinence to reasoning about abortion, and which are often deployed, either explicitly or implicitly, to dissuade women out of that reproductive choice. The first is that postabortion regret renders an abortion morally unjustified. The second is that that a relatively high incidence of postabortion regret - compared with a lower incidence of postnatal regret in the relevant comparator field - is good evidence for the moral impermissibility of abortion choice. The third is that high rates of postabortion regret suggest that abortion is not the most prudent or welfare-maximising choice for the woman concerned. All three theses argue for the compellingness of knowledge about postabortion regret in moral and practical reasoning about abortion, especially from the pregnant woman's point of view. This article argues that all three theses are flawed. In particular, it seeks to remind readers that feelings of regret directed at past decisions are often decoupled from the fact of the matter about their moral or rational justification. Moreover, certain features of reproductive decisions in particular make regret an especially unsuitable yardstick for actual justification in this context, and even less epistemically reliable as evidence for a lack of justification than it may be in other fields of decision-making. The implication is that rates of postabortion regret, even if they can be presumed to be higher than rates of postnatal regret, are not as pertinent to moral and practical reasoning about abortion as is sometimes suggested.

\section{LOOKING BACKWARDS: POSTABORTION REGRET AND AFFIRMATION}

It may well be an inescapable fact of life that abortion and regret go hand in hand in a way that childbearing and regret simply do not. Even regardless of sociological findings, the idea that women on the whole experience (and, for what it is worth, express) far more regret over aborted pregnancies than they do over becoming mothers is one that strikes as credible and intuitively compelling. A relatively higher coincidence of abortion and regret is thought by some to add weight to the argument against the moral justification of abortion, and more specifically, is presented as relevant information for those in the midst of reproductive decisionmaking. Rhetoric about postabortion regret and its meaning is a persistent feature of abortion discourse, especially in antiabortion advocacy. The idea that abortion and regret go together is both covertly and explicitly channelled through various media. 'Pro-life' pregnancy counselling services such as CareConfidential and internet discussion forums like Abort73 litter their web pages with stories of women who avowedly regret their abortion decisions, describing them as a terrible mistake with only negative repercussions ("...I regret my decision hugely...the regret afterwards is a horrible, horrible feeling"). ${ }^{i}{ }^{2} 2$ The ProLife Alliance describes abortion as a procedure which many women come to 'bitterly regret', and notes that 'while many women regret having their abortions, few regret having their babies'. ${ }^{3} 4$

But though the strong association of abortion with regret is rife in antiabortion discourse, the exact nature of the proposed connection can often seem obscure. Does regret make an abortion morally wrong? Does it make it more likely that an abortion was wrong? Does it simply suggest that the abortion was a bad idea for the woman concerned-that it was not in her individual interests? The drift of the message at least seems clear. That regret follows abortion around like a bad smell is a reason not to have an abortion. It is a reason to opt for an alternative solution to an unwanted or ambivalent pregnancy, namely motherhood or adoption.

But what is the main idea behind the putative relevance of regret to reasoning about abortion? The answer may seem, at first, fairly obvious: it mirrors the relevance of regret to any other, more mundane, decision in life. Say you are thinking of buying a car, and it happens to be the case that $80 \%$ of people who buy that particular make and model of car regret the decision with hindsight. Surely you would want to be informed of this fact, and would regard it as critical information when it comes to deciding whether or not to buy. As in everything else, one might argue that the likelihood of regretting abortion should logically inform the reasoning process of those in the throes of crisis pregnancies. From this vantage point, the relevance of regret might be said to go to the very rationality of the pregnant woman's decision. In line with this notion, proponents of broadly antiabortion views are quick to point out the 'psychological costs' of abortion which are thought to reveal how many women come to perceive their choice negatively in its aftermath. In a recent book, and as part of a much wider antiabortion argument, Christopher Kaczor notes that 'after the choice of abortion, many women bear a burden of guilt that is, for some, never terminated'. ${ }^{5}$ Many, he claims, 'regret and suffer because of their abortions', and to this end he refers to a selection of psychological studies which suggest that women who have undergone abortions carry a significantly higher risk of future psychiatric problems, substance abuse and even suicide..$^{6-8}$

Kaczor concedes that some women who have had abortions are firmly satisfied that they chose the correct option; clearly not everyone deeply regrets ending her pregnancy. However, he treats it 
as extremely meaningful that women who, in similar circumstances (that is to say, confronting unwanted pregnancies) choose to complete their pregnancy are 'virtually all glad that they did not have an abortion', including even those who initially wished for one. ${ }^{\text {ii }}$ While they might well still testify that the choice to have the child was the most difficult choice they ever faced, 'they are satisfied with themselves in this regard and live without regret'. He continues:

What woman mourns the anniversary of her child's birth? But how many women mourn usually in silence the anniversary of an abortion? What woman looks at her child and says "If only I had aborted her?" But how many women consider in the quiet of their hearts, "If I hadn't had the abortion...?" No group calls itself "Women Exploited by Giving Birth" or "Women Victimised by Giving Life." Yet many groups exist to comfort women hurt by abortion such as "Women Exploited by Abortion" or "Women Victimised by Abortion", organisations with thousands of members. No books are published to console women who gave birth rather than aborted. But how many books are published, from both pro-choice and pro-life perspectives, to help women with post-abortion grief?

It is important to note here that psychological trauma and regret are distinct emotional phenomena, though they may coincide. It is entirely plausible, for instance, for a woman to be psychologically scarred by giving birth (to the extent that she never wishes to go through it again) but to not regret it. However, when antiabortion writers invoke regret in this context, they do not mean to invoke a mere psychological or emotional reaction; rather, what they refer to is a retrospective judgment about the wrongness of the abortion decision, though that judgment itself may have predictable emotional and psychological by-products.

One should also be attentive to what such contestants consider to be the particular object of regret for many women who feel negatively about their abortions. It is possible for a woman to regret an abortion in a number of different ways. She may regret that life was such that she had an abortion or that life was such that it was reasonable only to have an abortion. She may regret that she became pregnant in the first place, and any number of decisions which led to that circumstance. However, according to Kaczor, the burden of guilt that is for some women 'never terminated' is directly related to the choice to end the life of the fetus. In this respect, it is also very different from the 'postpartum' depression that can follow miscarriage. Unlike postpartum depression (which stems straightforwardly from the loss of the fetus) and unlike mere regret that an abortion was necessary, it is regret that, once pregnant, she decided to end the life of the fetus, rather than allow it to continue. It is the kind of regret which we might also understand to entail remorse.

\section{Do women regret their abortions?}

For what it is worth, it might be noted that the conclusions of some recent high-profile studies undertaken suggest that most women do not regret having first-trimester abortions, or for that matter experience overwhelmingly negative emotional reactions to them. One such study published by psychology professors in the University of California sampled 442 women 2 years after their first-trimester abortion of which $69 \%$ said that they would have their abortion again, while $72 \%$ reported more benefit than harm resulting from the abortion, and $80 \%$ did not experience any depression at all. ${ }^{9}$ Those women who did experience psychological problems or regret 2 years postabortion tended to be women with a prior history of depression.
Commenting on the study in the Archives of General Psychology, Professor Nancy Adler remarked that its findings were "consistent with other well-designed studies' of its nature and bolstered the earlier conclusion by an expert panel convened by the American Psychological Association 'that abortion is generally "psychologically benign", 10

A yet more recent study published in the British Journal of Psychology in 2009 found that $90 \%$ of the 500 women sampled still believed, in retrospect, that having an abortion was the right decision, although its findings also 'clearly suggested' that unwanted pregnancy leading to abortion heightened the risk of developing subsequent mental problems, 'whereas unwanted pregnancy leading to live birth was not a risk factor for these problems'. ${ }^{11}$ The results broadly indicated 'a mixture of both positive and negative emotions' associated with abortion, with researchers pointing out that the 'accumulated evidence' on this topic is not consistent with claims by pro-life advocates that large numbers of women regret having abortions or their depiction of abortion as having 'devastating consequences for women's mental health'.

Still, according to Kaczor, the relevant claim is not that most or even many women come to regret their abortions, but just that more women regret having abortions than women who in similar circumstances choose to have their babies regret becoming mothers, and that there is a higher relative risk of certain psychiatric disorders among women who have had abortions than among the women in that comparator field. The research I have referred to here is broadly consistent with this claim (although it is of course imperative that such studies adequately account for other causative factors before they can be deemed credible). ${ }^{\text {ii }}$ Despite this, there remain reasons not to take such conclusions about relative rates of regret at face value. This is because of the compelling, if somewhat bleak, consideration that what women who carry initially unwanted (or unplanned) pregnancies to term ultimately express by way of regret or affirmation, and what they genuinely feel about childbearing may not correlate. It is, to say the very least, a serious social taboo for a mother to openly lament the decision to bear her child, and commentators cannot altogether neglect the distorting effect this may have on data measuring regret.

Conversely, women who do undergo abortions may be culturally conditioned or required to fit their subsequent reflections into a certain expressive framework, typically packaged in the language of regret. Women are told to expect that their abortion will be a 'painful part of their lives', something they will 'have to come to terms with' and may never entirely 'get over'. Even in countries where abortion is largely legal, it is rarely socially acceptable for a woman to express complete satisfaction with her decision to have an abortion and to attest to no pangs of uncertainty. Such social norms also have to be taken into account when collating the publicly-expressed attitudes of women who do speak about their abortions.

\section{THREE THESES}

It is by no means obvious, then, that most women regret having early abortions, and as seen, some studies have concluded precisely the opposite. Kaczor claims, however, that what really matters is simply that more women regret having abortions than women in similar circumstances regret giving birth, and it seems that the ProLife Alliance thinks in similar terms. I have suggested that there may be a reason to question whether even this claim is really true. Still, let us grant for the sake of argument that it is. What then? It is next necessary to ask precisely what bearing this has, or ought to have, on moral 
and practical reasoning about abortion. For Kaczor, the relatively high rates of postabortion regret shed light on the comparative psychological and emotional burdens of abortion vis-à-vis childbirth, lending considerable support to the case against aborting unwanted pregnancies. This is the relationship which we may say mirrors the relevance of knowledge about consumer regret over buying a particular model of car. It might be thought to heavily determine a woman's rational or prudential justification for having an abortion. If she is concerned about making a decision which most enhances her well-being, then perhaps she should not choose an option she is likely to regret.

But the meaning of regret in abortion may be thought to go much deeper than this. That is, high rates of postabortion regret can be thought to lend support to the antiabortion argument not just in terms of women's welfare-what might be regarded as prudential or self-regarding reasons for or against abortion-but in terms of overall moral justification. In other words, the relatively higher rate of regret over abortion could be taken to count towards its moral justification for reasons independent of the well-being of the pregnant woman (and as such can be propounded as part of the resolution of the fetalmaternal conflict). This of course is a very different sort of claim. Though Kaczor does not explicitly tie postabortion regret to the question of moral justification, his remarks about the specific object of regret-the decision to bring about the death of the fetus-loosely suggest that such feelings are indeed rationally appropriate and ought not to be regarded as purely pathological. And if postabortion regret, directed at that particular object, is understood to be appropriate, it is plain to see that a connection with abortion's moral impermissibility is subtly forged. For many opponents of abortion, the burden of guilt that is, for some women, 'never terminated' should not be disregarded as incidental or irrational, but rather should guide the detached observer towards the conclusion that there is something to be regretted, because abortion is the morally wrong choice.

The proposition that high rates of postabortion regret are indicative of abortion's moral impermissibility can in fact be further divided into two separate claims. One possible claim being made is that regret over an abortion renders that abortion morally unjustified. A different claim is that high rates of postabortion regret are simply strong evidence for abortion's broad moral impermissibility. In other words, the relationship between regret and moral justification in abortion is an epistemic one. If either of these two relationships between abortion and regret hold, it is possible to see why knowledge about rates of regret or the likelihood of oneself regretting an abortion could be relevant to determining whether or not the decision is morally justified.

Let me restate the three putative connections between the justification of abortion and postabortion regret:

1. The moral justification thesis: postabortion regret renders an abortion morally unjustified.

2. The epistemic thesis: high rates of postabortion regret (relative to the relevant comparator field) are good evidence for the moral impermissibility of abortion.

3. The rational justification thesis: high rates of postabortion regret suggest that abortion is an imprudent or unreasonable choice.

I now wish to demonstrate that none of the theses holds up under scrutiny and that this is particularly evident when directing one's attention to certain unique features of reproductive decision-making. My conclusions, if correct, will in turn cast doubt on whether it is ever appropriate to harness postabortion regret for the purposes of arguing about the morality or prudence of abortion. Moreover, if the three theses are shown to be inherently flawed, there will be no need to resort to debunking explanations of the available data in order to denounce the proposed relationships between justification and regret in abortion. Rather, one will be perfectly able to concede that it really is rare for any woman to regret choosing childbirth over abortion and still maintain that regret has very little, if anything, to say about abortion's moral or rational standing.

\section{THE MORAL JUSTIFICATION THESIS}

I begin with what may be regarded as the most contentious of the three theses: that regret is constitutive of an abortion's lack of moral justification. In other words, the fact that a woman regrets having an abortion is enough to make that abortion morally unjustified. I wish to show that the thesis is problematic because it rests on a foundational premise which can be shown-especially in this context-to be false: that regret necessarily 'tracks' moral justification in decision-making. Put differently, it is the idea that regret and moral justification go hand in hand, so that whatever one regrets doing must be unjustified.

It may be wondered whether contesting such a thesis is in truth only attacking a straw man, for who sincerely espouses the view that a woman's regretting an abortion makes it morally unjustified? It is true that antiabortion campaigns tend not to advocate the thesis in clear terms. However, much of the discussion of regret on forums like those mentioned above is notable for failing to account for its antithesis. By this I mean that there is little to no room made for the possibility that even if an abortion decision is regretted, this may not mean that it was morally wrong. Instead, the tales of regret appear to be posited as completely settling the moral question as well as the rational one for the woman concerned. At the very least, the failure by such websites to even distinguish between the meaning of regret for moral and rational justification suggests that such discussants treat the questions as wrapped into one, and that if a woman regrets an abortion, this fact alone is reason to believe in the moral error of her choice.

The binding of regret to moral justification in this way is not entirely without philosophical support. In particular, the philosopher Bernard Williams suggested that one's actions could be morally unjustified in virtue of a certain kind of regret, noting the ostensible implication to be some measure of 'moral luck', this meaning, as Williams explains it, that it can be 'a matter of luck that someone was justified in doing as he did' iv 12 Williams describes the particular species of regret as 'agent-regret'. Agent-regret is regret not just over how things turned out - that certain states of affairs might have been otherwise-but entails a wish that one had acted otherwise. Williams's argument is that we often come to experience such regret over our actions because of outcomes not entirely within our control. The lorry driver, who, through no fault of his own, runs over a child that steps into the road is likely to feel deeply regretful for his actions notwithstanding that he is not to blame, because of the unfortunate turn of events. Williams therefore claims that agent-regret is largely dictated by uncontrolled consequences and that this is suggestive of the existence of moral luck. ${ }^{v}$ However, as the philosopher R Jay Wallace points out, the susceptibility of agent-regret to luck is not evidence for the moral luck thesis - that the moral justification of one's decisions or actions is itself hostage to fortune-unless another premise is 
also true: that regret tracks moral justification. That is to say, the fact that someone experiences agent-regret over a decision or act is pertinent to his moral justification for acting in such a way only if it is true that regret and moral justification are aligned. And this is precisely the same premise that would be required to uphold the claim that postabortion regret entails the moral incorrectness of an abortion. To say that the rights and wrongs of abortion are dictated by agent-regret is to accept the claim that regret and moral justification go hand in hand. The claim, however, is a highly suspect one. In a recent paper, R Jay Wallace illustrates its falsity with the use of a helpful example. ${ }^{\text {vi } 13}$

\section{The young girl's child}

The example Wallace uses is Derek Parfit's account of 'the young girl's child' which, he believes, poses a challenge to the idea that one's retrospective attitude towards a decision will necessarily follow its justification. ${ }^{\text {vii }} 14$ We are asked to imagine a 14-year-old girl who decides to conceive a child in circumstances where the girl's immaturity creates a strong moral objection against intentionally becoming a mother at such a young age. We can imagine that the objection attaches to concerns for the girl's own welfare and that of the child, it being irresponsible towards the child to bring it into the world when she is ill-prepared to meet all of its needs.

A sharp problem thrown up by the example is the problem of 'temporal perspective'. Let us say we are convinced that at the time the girl makes the decision it would have been better that she chose differently and delayed motherhood. However, if it is true that it would have been better at the time that the girl did not conceive, this fact must remain true in retrospect, in which case the girl, if she eventually comes to appreciate those objections, would seemingly have to concede, looking back, that it would have been better that the child had never existed. The problem here is that once the child is born the girl will find it difficult to regret its existence. In this respect her attitude is not merely arbitrary, as Wallace explains, 'it is not just that she happens not to regret her child's existence' now that it has actually arrived; rather, she has good reason not to regret its existence. This is owed to a change in the girl's deliberative situation brought about by the birth of the child. Once the child is born, it is no longer an open question for the girl whether or not to bring it into the world. There is now, Wallace explains, a new human being on the scene, who makes a claim on her in a way that 'merely possible people do not'. Responding appropriately to that claim-in other words, living up to her duty as a mother-requires her to affirm and celebrate the existence of her child, and this is incompatible with regretting her decision to conceive.

Again, we should not be too quick to discount the possibility that some women do regret having their children, whether they express it or not, and I do not think Wallace means to argue that such regret is impossible. However, the proposition that mothers have a reason not to regret their children's existence, and even a duty not to regret it, is a compelling one. If this is correct, Wallace argues, then it seems that the girl will have made 'a mistaken decision that is inaccessible to regret', since the fact that she now finds herself unable to regret her child's existence does not temper the moral objections to conceiving a child when she was still a young teenager; even she may still accept, that she ought not to have had a child so early in life. It appears that justification and regret (or affirmation) in this example can indeed come apart-that the one does not follow from the other.

\section{The objects of regret}

But is it not possible that the young girl can in fact regret her decision to become a mother so young, while at the same time refuse to regret her child's existence? Maybe she can separate out in her attitude the object of regret (her decision) and affirmation (the child's life), in which case it will follow that her feelings of regret over her decision do 'track' the moral justification issue. Wallace's answer to this query starts with an observation about the 'totalising' character of regret. In short, regret is an attitude formed in light of the totality of things which have taken place. This, at any rate, is what Wallace refers to as 'all-in' regret, which is an 'all things considered' judgment of a past act, event or circumstance, 'taking into account the totality of subsequent events' that were set in motion by it.

Importantly, all-in regret cannot coexist with all-in affirmation of the relevant past act, event or circumstance. If I am glad all things considered that I made a certain decision in the past because of the events which led on from it, then I cannot at the same time (at least, coherently) truly regret the decision in the sense that entails a wish that I decided otherwise. Nevertheless, Wallace points out that often it is possible to distinguish in one's backward-looking attitude between the object one regrets and the object one affirms in an overall chain of events. He gives the following example:

I am glad we went on a punting expedition yesterday, but I am sorry we got caught in a rain shower.

This he describes as a 'parsing manoeuvre'. In short, the parsing manoeuvre allows us to hold differently valenced attitudes towards separate objects in the same sequence of events in which they are both a part. By means of the parsing manoeuvre, all-in regret can coexist with affirmation targeted at distinct aspects of the whole chain of events being contemplated, and indeed, the inverse (as in the example), where one all-in affirms an event or circumstance yet regrets one of its aspects. However, sometimes this parsing strategy cannot apply Suppose, Wallace suggests, that I break my promise to drive you to the airport, with the result that you miss your flight. Later, though, it is discovered that the flight you intended to catch crashed with the result that all the passengers were killed. Clearly you will be incapable of all-in regretting that I failed to pick you up as promised. But neither, Wallace argues, can you avail yourself of the parsing strategy and pick out my broken promise as a distinct target of regret in an all-in affirmed sequence of events. This is because the putative distinct object of regret - the broken promise-is a necessary condition of the circumstance that is the target of all-in relief and affirmation. Since you would not have been saved but for my broken promise, you cannot coherently isolate my wrongful act as an object of regret.

Wallace claims that the structure of the young girl's child example reflects that of the plane crash case. If the young girl all-in affirms the existence of the child, she cannot specifically regret her decision to conceive at a young age, for apart from that decision, the child would not exist. This is also why the girl cannot just adopt the parsing strategy by being glad for the life of her child but regretting her decision to have her at that particular time, for the scenario in which the girl does put-off motherhood is a counterfactual which is incompatible with that child's existence. Had she delayed, the girl would still have a child, but not the same one. Yet it is that particular child's existence which she is duty-bound to celebrate. ${ }^{\text {viii }}$ As in the 
plane crash case, there is no separating out her all-in affirmation from the particular putative object of regret. It remains crucially important though, as Wallace explains, that in both cases the moral objection to the relevant act (the broken promise and the decision to have a child too young) is unaffected by the fact that it is not or ought not to be regretted. You may still have a moral complaint against me for breaking my promise and failing to take you to the airport, even though you cannot regret it. Likewise with the young girl, her ultimate inability to regret her decision does nothing to eliminate the moral objections to it at the time of her deliberations. She (as we) can continue to hold a separate judgment about her decision, according to which its objections retain their moral force in its wake and it remains unjustified. When turning her thoughts to that moral objection, Wallace suggests that the girl's attitudinal response is likely to take the form of some version of remorse-sadness, perhaps, that she was not better prepared for motherhood-which nevertheless falls short of all-in regret, an attitude which, as a mother, she now cannot countenance. The girl's emotional ambivalence stems from the fact that she is fundamentally unable to regret a decision which continues to be subject to powerful objections.

\section{Abortion and childbirth}

Wallace's analysis is first and foremost instructive in showing that regret does not invariably track moral justification, or rather, its absence. Though the example he uses is that of a decision whether or not to conceive, it is evident that the same conclusion - the decoupling of retrospective attitude and justification-holds for abortion decisions as well. Suppose that the decision facing the young girl is not whether or not to conceive, but whether or not to continue a pregnancy. Should she choose to carry the pregnancy to term, she will ultimately find herself in the same deliberative situation as the young girl in Wallace's example, subject to a parental duty to affirm the life of her child, which will preclude regret over her reproductive choice. ${ }^{\text {ix }}$ Imagine further that at the time of her choice there may have been serious objections to continuing the pregnancy. If this was the case, then such objections would continue to stand even if the girl chose to complete her pregnancy, thus finding herself in a position where she could not regret her choice. As Wallace's analysis shows, the inaccessibility of regret in this scenario does not settle the question of justification since the girl is dutybound to affirm her choice whether or not it was in fact justified.

But suppose instead that she chooses to terminate the pregnancy whereupon she later comes to regret that choice. Her retrospective attitude cannot be conclusive of moral justification here either: it may yet have been the morally correct choice. That question will stand equally unaffected by her later attitude, whether it is regret or affirmation. Furthermore, that we happen to know that regret would have been inappropriate or inaccessible had she decided to complete the pregnancy does not change this. In the childbirth scenario, we are already aware that regret would be inappropriate in any case because of the nature of the girl's deliberative situation. If the girl chooses instead to have a termination, she will not be thrust into the same deliberative situation where she is bound not to regret her decision; a woman who has an abortion does not owe it to anyone to look back on her decision with approval. But this asymmetry in the accessibility of regret does not render it more likely that postabortion regret would track the moral justification question. If the girl has her baby, we know that the nonavailability of regret has nothing to do with justification. The presence of regret in the abortion scenario does not therefore take on justificatory significance simply because, had she kept the pregnancy, she would eventually have to affirm her decision.

\section{THE EPISTEMIC THESIS}

The foregoing might be considered a rather lengthy refutation of what is, in any case, a highly contentious thesis: that moral justification tracks regret in abortion. But understanding how the moral justification thesis can be shown to be wrong-particularly through the prism of Wallace's analysis-has another pay-off, in that it helps us to see why the epistemic thesis also fails to convince. To reiterate, the epistemic thesis claims that a relatively high rate of postabortion regret is a good indication of abortion's moral impermissibility. As we saw earlier, it is far from clear that most women do in fact regret their early abortions or experience negative emotional reactions associated with regret. Nevertheless, I accepted for the sake of argument the more supportable claim that more women experience postabortion regret than similarly situated women experience postnatal regret (as I pointed out, this suggestion is consistent with the research mentioned, although it may yet be susceptible to alternative explanations). But I believe the epistemic thesis would be flawed even if the stronger claim were true, that is, if many or even most women regretted their abortions. Let us assume then, that this is the case: that abortion begets regret in most cases. Would it be a reason to suspect abortion of being morally impermissible?

First, the regret alluded to would again have to target the right kind of object for it to suggest anything about moral impermissibility. People may regret decisions for all sorts of reasons which have no bearing on their moral soundness. Many people might regret buying a certain model of car because it depreciates quickly, and this would not be a reason to think that buying the car was impermissible. For moral permissibility to be implicated, the specific object of regret would have to meet Kaczor's characterisation, namely, the decision to end the life of the fetus, and take the form of guilt directed at that decision. So let us also grant that this really is the nature of postabortion regret as commonly experienced. If one happens to know that most people come to experience guilt over a certain decision, is this not enough reason to suspect that decision of being morally defective?

It is perhaps true that such a finding should give one pause for thought. But far more would need to be established before it should be accepted as evidence of abortion's moral impermissibility. Specifically, one would have to be satisfied that there are no compelling explanations for postabortion regret other than abortion's moral problematicness. However, Wallace's description of the young girl's child example helps to reveal a very credible alternative explanation. As with the young girl, where a woman chooses to carry a pregnancy to term and bear a child, she will alter her future deliberative situation so that regret over her decision will become inappropriate once her child is born. As I said, this does not mean that she will be altogether incapable of experiencing regret, but that she has an important reason not to embrace that attitude, emanating from her maternal duties. On the other side of the coin, women who choose to terminate pregnancies are under no such parallel duty to celebrate and affirm their decision in retrospect. Given that they are under no such duty-to anyone else, or to themselves-it would first be completely unsurprising to learn that they experience regret more widely than the alternative group. They are under no duty not to form such an 
attitude. The counterfactual is one in which they have nothing that it is appropriate to regret, whereas it is not altogether inappropriate to regret an abortion.

This asymmetry of duties aptly explains why we should expect a higher rate of postabortion regret compared with postnatal, but it might be objected that it would fail to explain why so many women regret abortion, if this happened to be true. Women who have abortions are not duty-bound to affirm their choice, as mothers may be, but neither are they compelled by any duty to regret it. With both retrospective attitudes open to them, might not a high frequency of regret still count as evidence for abortion's moral impermissibility? Of course, it is entirely possible for whole swathes of people to be mistaken in their retrospective assessment of a decision. But the challenge set by antiabortion advocates might be to explain why postabortion regret would recur with such high frequency if it is not informed by the realty of the moral situation. This, however, is not a difficult task.

First, much might be revealed by considering the effects of the asymmetrical duty discussed on human psychology. With the locus of fear and panic (the unwanted pregnancy) now removed, women who have abortions are left only to dwell on a counterfactual in which they would have a child whose existence they could not but celebrate, even if it were concomitant with challenges for which they are unprepared. This may be partly a function of imagination and its respective limits in the alternative scenarios. Serious psychological barriers may stand in the way of mother's ability to imagine life without a child she now knows and loves, and especially to view such a counterfactual in a positive light. In contrast, women who have abortions do not contend with the same impediments if and when they imagine life with the child they chose not to have. Though there may be goods in their lives incompatible with that counterfactual (career success, greater freedom of movement and so on) the mental exercise of imagining them away may not come up against the same level of psychological and emotional resistance, freeing such women up to concentrate on what they might have lost, rather than forcing them to think only of what they have gained.

Second, I have already mentioned the possible influence of cultural attitudes towards reproduction on what women express about abortion and childbirth. If this is plausible, then there is equally reason to suspect that cultural norms will affect the retrospective attitudes women actually form. It is possible that social expectations account for the actual experience of postabortion regret every bit as much as they account for its expression. There is a persistent message that abortions are to be regretted, that it is appropriate to regret them and that they are a dark blot on a moral record which it can only be hoped will never be discovered. The sheer rareness of women willing to publicly admit to having an abortion attests itself to the widespread moral condemnation of - at best, the public ambivalence towards abortion choice, and one cannot disregard the impact this has on the retrospective attitudes of those women who opt for it.

Women who have abortions have no duty-based reason to affirm their decision in retrospect, are left to imagine only a counterfactual scenario where regret is inaccessible, and are socially encouraged to believe and express the sentiment that their decision was morally erroneous. All of these considerations can provide a ready explanation as to why so many women regret abortions, and not child-bearing, without suggesting anything about the moral impermissibility of opting for the former.

\section{THE RATIONAL JUSTIFICATION THESIS}

Perhaps, though, the discussion so far has only strengthened the third and final thesis about abortion reasoning and abortion regret. Faced with the dilemma of whether or not to continue an unwanted pregnancy, the pregnant woman might truthfully be told that whereas she will not reasonably be able to regret continuing the pregnancy, the same cannot be said if she terminates. Should not she choose the course of action that she cannot reasonably regret? Presuming that a life which carries serious regret is the worse off for it, it might be suggested that the rational course of action is to choose the option which simply bars it. Hence, the relative likelihood of postabortion regret undermines the rational justification for abortion.

What is amiss in this reasoning? We can certainly understand why the avoidance of future regret can be a pertinent consideration in determining the rationally best course of action, but only insofar as that regret is parasitic on a failure in rational deliberation. Returning to the car example from earlier, the reason why high rates of consumer regret should dissuade the new customer from buying the car is that it suggests the car was a bad choice for all of the reasons that are important in the customer's initial decision-making process (the car's durability, efficiency, depreciation rate, etc). But when it comes to abortion and childbirth, the asymmetry in attitudinal duties (the mother must affirm her reproductive decision; the women who has an abortion need not) undermines the relationship between retrospective attitude and best choice. The woman who becomes a mother will be duty-bound to celebrate her decision whether or not it was the optimal one for her and her well-being. Consequently, if the inaccessibility of regret to mothers is invoked as a reason to choose against abortion, this cannot be because it suggests that the abortion is unlikely to be rationally justified. It can only then be the avoidance of regret per se which is being propounded as a reason to choose against abortion. You should choose the course of action which certainly avoids regret, whether it is the best one or not.

The idea that avoiding regret is, in and of itself, a reason for acting in a particular way is an interesting one. It is of course difficult to imagine that the resistance of a particular course of action to regret could be a reason for doing it. The exhortations "go on a long walk today, you won't regret it" or "have children, you won't regret it" fail to provide any positive reason for following the suggested course of conduct. We usually require more in the way of reasons for doing things than that we will not regret them. On the other hand, the possibility or likelihood of regretting an action or decision can be intelligibly deployed as a reason against that course of conduct ("don't go out in the rain, you'll regret it"). If there is a decent chance of one's regretting an abortion, then, perhaps this ought to count against the decision.

However, when regret is deployed as a negative reason in this way ("don't go out in the rain, you'll regret it"), its persuasive power only derives from the belief that the regret will reflect justification. What is really meant by 'don't go out in the rain, you'll regret it' is 'you will regret it because it is imprudent'. In other words, it is merely a more powerful way of impressing on a person the folly of an action which does not derive from its propensity to cause regret. Yet this is not the same thing as invoking the possibility of experiencing regret as a reason itself to avoid the action. This would only be sound reasoning if it were the case that experiencing regret over the relevant thing was so bad for a person, and so ruinous, that absolutely ensuring its avoidance is a consideration which trumps all other 
reasons in favour of a course of conduct. But in most cases this would be to wildly exaggerate the impact of regret on people's lives. Living with regrets does not mean that one's life is dominated or seriously marred by those regrets, which may be reflected on only from time to time.

Returning to the young girl in the crisis pregnancy, it is clear that the question of what is best to do is still one that she must grapple with at the time of the decision, and that she cannot be helped along by the understanding that she would, in any event, ultimately be unable to regret choosing motherhood. Since the choice which maximises her own well-being will not inevitably be the choice which leaves her with no regrets, she will fail to engage in serious reasoning about what best to do if she merely exchanges the sum of reasons for or against procuring a termination for a conclusion on how best to avoid experiencing future regret. That a decision may yield regret is not enough, by itself, to suggest that it is the wrong one, and as we saw, regret over abortion decisions in particular can often be encouraged by factors not having to do with the moral justification of the decision or its effect on women's welfare. Consequently, using the possibility or likelihood of regrets to deter women from abortion is rationally unfounded at best, and at worst, emotionally manipulative.

Nothing I have said here is meant to be conclusive of the moral permissibility of abortion, which I believe substantially depends on what moral standing is rightly accorded to the fetus. My aim has only been to disqualify knowledge about postabortion regret as salient to that question, and to others.

i Though the content of the counselling sessions are themselves private, one can well imagine how the use of regret can be (and probably is) deployed in such discussions to encourage what the counsellors deem to be the best outcome to a crisis pregnancy.

ii Emphasis added.

iii By 'other causative factors' I refer to a host of potential sources of psychological instability which, although they are not the result of abortion, may be contingently likely to affect women who opt for it (social and economic deprivation; relational instability, personal insecurity and so forth).

iv It was Bernard Williams who coined the term 'moral luck' and believed that it entailed some kind of oxymoron. The moral luck thesis is naturally far richer than it is stated here and could be defined in numerous other ways.

$\checkmark$ One possible ambiguity in Williams's thesis is created by his use of the term 'rational justification' at times to describe the phenomenon that is subject to luck. Despite this, it is nonetheless clear that Williams considers his observations about agent-regret as evidence of that one can be morally justified in respect of consequences partly beyond one's control (hence he posits it as an argument for the 'moral luck' thesis).

vi The terminology of regret 'tracking' justification is Wallace's own. vii Parfit himself uses the example in the service of making a different philosophical argument about the impersonal dimension of value judgments.

viii Similarly, in the plane crash example, you may well say to me, the promise-breaker: "I wish my salvation had come in some other form than your promise-breaking", but this wish invokes a completely counterfactual scenario. The attitude expressed by 'all-in regret' or affirmation is, in contrast, definitively targeted at the sequence of actual events. However much you wish that all of the events had been ordered otherwise (you can just as readily wish that you had never booked the flight in the first place), these kinds of wishes will not affect your 'on-balance' attitude towards my particular act of promise-breaking, when situated in the real and actual chain of events.

ix It is possible that there are exceptions to this, such as where a child is given up for adoption. We may not think in such a case that the biological mother is under any obligation towards the child not to regret her decision to become pregnant, given that someone else has taken on the necessary life-affirming role of being that child's parent.

Acknowledgements The author would like to thank Leslie Green and Imogen Goold for helpful comments.

Competing interests None.

Patient consent Obtained.

Provenance and peer review Not commissioned; externally peer reviewed.

\section{REFERENCES}

1. http://www.careconfidential.com/PeoplesStories.aspx (accessed 19 Jun 2012).

2. http://www.abort73.com/testimony/ (accessed 19 Jun 2012).

3. http://prolife.org.uk/2012/01/informed-consent-victory-in-texas/ (accessed 17 Jun 2012).

4. http://prolife.org.uk/2012/06/after-a-long-silence-an-abortion-doctor-speaks-at-last/ (accessed 17 Jun 2012)

5. Kaczor C. The ethics of abortion: women's rights, human life, and the question of justice. New York: Routledge, 2011:173-5.

6. Reardon DC, Cougle JR, Rue VM, et al. Psychiatric admissions of low income women following abortion and childbirth. Can Med Assoc J 2003;168:1253-7.

7. Morgan CL, Evans M, Peters JR, et al. Mental health may deteriorate as a direct effect of induced abortion. BMJ 1997;314:902.

8. Gissler M, Hemminiki E, Lohnqvist J. Suicides after pregnancy in Finland, 1987-94. BMJ 1996;313:1341-4.

9. Major B, Cozzarelli C, Cooper ML, et al. Psychological responses of women after first-trimester abortion. Arch Gen Psychiatry 2000;57:777-84.

10. Adler N. Abortion and the null hypothesis. Arch Gen Psychiatry 2000;57:785-6.

11. Fergusson DM, Horwood J, Boden JM. Reactions to abortion and subsequent mental health. Br J Psychol Gen Sect 2009;195:420-6.

12. Williams B. Moral luck. In: Williams B. Moral luck. Cambridge: Cambridge University Press, 1982:20-39: 22.

13. Wallace RJ. Justification, regret, and moral complaint: looking forward and looking backward on (and in) human life. In: Heuer U, Lang G, eds. Luck, value and commitment, themes from the ethics of Bernard Williams. Oxford: Oxford University Press, 2012. The quotations here are as they will appear in the final version of the paper. Page numbers are currently unavailable, Forthcoming .

14. Parfit D. Reasons and persons. Oxford: Clarendon Press, 1984:357-61. 